\title{
REVISTAMARACANAN
}

Dossiê

\section{A Diretoria da Agricultura sob a chefia de Machado Assis: Os processos de solicitação de compra de propriedade no Amazonas (1887-1889)}

\author{
The Agriculture secretary under Machado de Assis command: The property \\ requests and the former property system in Amazonas (1887-1889)
}

Pedro Parga Rodrigues*

Universidade Federal Rural do Rio de Janeiro

Seropédica, Rio de Janeiro, Brasil

Recebido em: 04 abr. 2019.

Aprovado em: 10 jun. 2019.

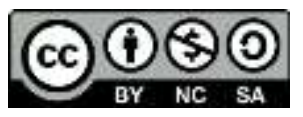

O presente trabalho foi realizado com apoio da Coordenação de Aperfeiçoamento de Pessoal de Nível Superior - Brasil (CAPES) - Código de Financiamento 001. Também contou com apoio recebido do Conselho Nacional de Desenvolvimento Científico e Tecnológico - Brasil (CNPq) - Edital Universal n. $28 / 2018$.

\footnotetext{
* Pesquisador em estágio de Pós-doutorado, pela Capes, no Programa de Pós-Graduação em História da Universidade Federal Rural do Rio de Janeiro. Doutor em História pela Universidade Federal Fluminense; Mestre em História pela Universidade Federal do Estado do Rio de Janeiro; graduado em História pela Universidade Federal Fluminense. (pedropargar@gmail.com)

ORCID iD: https://orcid.org/0000-0003-4876-9073

CV Lattes: http://lattes.cnpq.br/0455157958879373
} 


\title{
Resumo
}

Trata-se de analisar qualitativamente sete processos de solicitação de compra de terras devolutas provenientes da Amazônia. Estes foram analisados pelos funcionários da Diretoria da Agricultura do Ministério da Agricultura, Comércio e Obras Públicas entre 1887 e 1889. Neste momento, Machado de Assis exercia a função de chefe nesta repartição. Na medida em que abordamos a atuação desta diretoria na aplicação das leis agrárias oitocentistas, estaremos também percebendo algumas das contingências nas quais o Bruxo do Cosme Velho exerceu suas funções no funcionalismo público. Através da análise destes processos, percebemos como esta repartição tendeu a valorizar elementos do regime de sesmarias, o fundamento da posse e a capacidade para o cultivo, na aplicação da Lei de 1850. Partimos da concepção de Direito de E. Thompson segundo a qual a lei é um espaço de conflito, mas ainda assim favorece os grupos hegemônicos. Também pressupomos a compreensão segundo a qual a relação entre os homens e as coisas se transforma historicamente.

Palavras-chave: Diretoria da Agricultura. Segundo Reinado. Questão Agrária.

\begin{abstract}
That paper will qualitatively analyze seven property requests from Amazonia. They were analyzed by public agents from Agriculture Secretary, at the Agriculture, Commerce and Public Work Ministry, among 1887-1889. Thorough this time, Machado de Assis was working as chief inside this agency. As we consider how the ministry officials read the agrarian laws from $19^{\text {th }}$ century, we will also be realizing the social reality where Machado de Assis worked as a public agent. Analyzing those documents, we can perceive this division used to deal about the property, recurring to some previous rules and agrarian's customs. As they were applying a Land Law from 1850, they recurred to Sesmarias rules and the importance of the possession. They also valued the applicants able of producing on the demanded land. We assumed E. Thompson's comprehension about justice, considering the law as part of the social conflict and favors the hegemonic groups. We also will assume the fact that the property historically changes.
\end{abstract}

Keywords: Agriculture Secretary. Second Reign. Agrarian System. 


\section{Introdução}

Trata-se aqui de analisar sete processos de solicitação de terras devolutas na província do Amazonas submetidos à segunda seção da Diretoria da Agricultura entre 1887 e 1889. Todos estes documentos passaram pelo crivo de José Maria Machado de Assis, pois, desde 1876, ele atuava como chefe desta repartição do Ministério da Agricultura, Comércio e Obras Públicas. Ele havia sido integrado neste ministério na posição de oficial da Diretoria Central por ocasião da reforma ministerial de 1873, na qual este foi subdividido em quatro diretorias: Central, da Agricultura, de Comércio e de Obras Públicas. A segunda seção da Diretoria da Agricultura, na qual Machado atuou a maior parte do tempo de sua trajetória nesta pasta, era responsável por lidar com a questão fundiária brasileira. Desta forma, suas penas assinaram processos envolvendo conflitos de terra, invasão de aldeamentos indígenas, prazos de demarcação de propriedade, titulação de agrimensores e outras pendengas associadas ao universo rural daquele período. Aqui, destacaremos as requisições de terras no Amazonas nos anos de 1887 e 1889. A demarcação temporal surgiu a partir da análise das próprias fontes. Todas as requisições de terras referentes à Amazônia encontradas tramitaram nos órgãos neste intervalo de tempo. Nenhuma deixou de receber a assinatura e pareceres machadianos.

Não é possível, entretanto, inferir destes processos as concepções de Machado de Assis sobre a realidade agrária daquele momento. A maior parte de seus pareceres apenas ratificaram as propostas de seus colegas e subordinados. O seu discurso mais típico foi se restringir a palavra "concordo", muito embora tenha discordado em alguns momentos dos posicionamentos de outros funcionários da repartição. Foi mais comum ele discordar da Inspetoria de Terras Públicas e Colonização do que de seus subordinados. Esses desacordos nos permitem somente uma visão aproximada das perspectivas do funcionário Machado de Assis. Entretanto, a análise destes processos é elucidativa com relação às políticas agrárias dos momentos finais Império, possibilitando refletir sobre as contingências nas quais Machado atuou no funcionalismo público. Podemos pensar sobre quais eram os posicionamentos mais típicos no interior da Diretoria da Agricultura acerca das solicitações de compra de terras devolutas no Amazonas nos anos de 1887 e 1889. Assim, perceberemos os posicionamentos presentes no campo institucional no qual ele atuou como funcionário desta repartição. Estaremos, assim, contribuindo, em proporções diferentes, com dois temas ainda obscuros na historiografia, quais sejam, o exercício profissional de Machado de Assis na Diretoria da Agricultura e a forma na qual a mesma repartição operou a aplicação das Leis Agrárias oitocentistas. Embora todas as biografias mencionem o fato de o Bruxo do Cosme Velho ter trabalhado nesta instituição, nenhuma se dedicou a examinar estes processos. Mesmo os estudiosos da história agrária não se debruçaram sobre o Ministério da Agricultura, Comércio e Obras Públicas para pensar como seus agentes lidaram com a diversa realidade fundiária do Brasil no Segundo Reinado. 


\section{Uma visão geral sobre os projetos}

Encontramos 61 processos relacionados à questão fundiária que tramitaram na diretoria nas décadas de 1870 e 1880 . Trinta e oito (62,3\%) deles tratavam de requisição de terras por compra, sendo que dois ainda pediam outros favores do Estado. Oito requerentes solicitavam terras no Amazonas. Dois requerentes anunciavam como finalidade à extração de borracha. Outros dois pretendiam se dedicar à criação de gado. Um anunciava a edificação como objetivo. Enquanto os restantes não declararam o seu intuito. Todas estas demandas no Amazonas foram realizadas nos anos de 1887 e 1888. Tratava-se de um período de crescimento da extração da borracha. Segundo Francivaldo Nunes, "entre as décadas de 1830 a 1900, o crescimento da produção da borracha para exportação em toneladas saltou de 156 para $15.335^{\prime \prime} .{ }^{1}$ Cinco destes pedidos foram deferidos. Dois foram indeferidos e um caiu em exigência de provas das alegações do autor. Neste sentido, pouco mais de $62 \%$ das solicitações de terras desta província resultaram em despachos, provenientes da Diretoria da Agricultura, positivo aos demandantes. As cinco solicitações autorizadas por esta repartição informavam que os demandantes já possuíam, ocupavam ou produziam nos terrenos requeridos, enquanto as indeferidas deixavam de fazer o mesmo.

Os solicitantes de terrenos por compra geralmente argumentavam em favor de seus pedidos anunciando já estarem de posse das áreas desejadas. Flávia Darossi e Paulo Pinheiro analisaram vinte e quatro pedidos de compra de terras em Lages, Curitibanos e Campos Novos, municípios de Santa Catarina. Eles perceberam que $41 \%$ das solicitações demandavam "parcelas de terras públicas já ocupadas", demonstrando que "a manutenção de alguns dos principais preceitos da legislação sesmarial, que previam a regularização de terras ocupadas e empregadas com trabalho agrícola". ${ }^{2}$ As ordenações portuguesas referendavam a posse como forma de adquirir direitos sobre um bem. Caso o sesmeiro não ocupasse e cultivasse o terreno concedido para ele, a terra tornava-se devoluta, isto é, deveria ser devolvida ao monarca para este realizar nova concessão. Tratava-se, segundo Laura Beck Varela, do fundamento da posse. ${ }^{3}$ Da mesma forma, nas solicitações de compra de terras das décadas finais do Império, a posse continuava tendo uma importância jurídica, não obstante a Lei de Terras de 1850 ter

\footnotetext{
${ }^{1}$ NUNES, Francivaldo Alves. Por uma arte do cultivo: Agricultura como instrumento de controle dos índios e colonos no Pará das décadas de 1840-1880. Anais do [...]. XVII Encontro de História da Anpuh-Rio. Universidade Federal Rural do Rio de Janeiro, Nova Iguaçu (RJ), 2016, p. 4-5.

2 MACHADO, Paulo Pinheiro; DAROSSI, Flávia Paula. A política de acesso à terra no Brasil Imperial e a compra de terras devolutas no planalto da província de Santa Catarina. Clio: Revista de Pesquisa Histórica do Programa de Pós-Graduação em História da Universidade Federal de Pernambuco, Recife, v. 34, n. 2, p. 86-111, 2016, p. 105.

3 VARELA, Laura Beck. Das Sesmarias à propriedade moderna: um estudo de história do direito brasileiro. Rio de Janeiro: Renovar, 2005, p. 19-70.
} 
tentado sacralizar a compra como forma de aquisição dominial. Isto corrobora com a tese de Márcia Motta sobre a continuidade da importância do costume da posse após $1850 .{ }^{4}$

Cinco dos oito requerentes de terrenos do Amazonas informaram já terem ocupado previamente os territórios demandados por eles. Ao argumento da posse prévia, soma-se ainda o da capacidade do cultivo. Em diferentes autos, funcionários da Diretoria de Agricultura solicitam provas de que o peticionário conseguiria cultivar a área pedida. Esta capacidade era uma das exigências estabelecidas no Período Colonial para o rei realizar concessões de sesmarias. Os requerentes de terra da Amazônia tenderam a demandar terras previamente ocupadas. Esta realidade difere, por exemplo, das requisições de terrenos do Espírito Santo que encontramos também nas fontes da Diretoria da Agricultura. Os demandantes espíritosantense solicitavam terras contíguas as áreas já ocupadas por eles, tal qual previa a Lei de Terras de 1850. Esta diferença tem muito a dizer sobre a dinâmica de ocupação do território amazônico. Márcio Both apresenta, usando os relatórios da Inspetoria de Terras Pública e Colonização de 1886, inspetores alertando sobre a prática de posseiros pedirem por compra terras ocupadas irregularmente. Mesmo comentando sobre este costume, eles deixavam às claras o fato do governo coadunar com estas operações com o intuito de legitimar tais ocupações. De acordo com o historiador, "não há como negar que muitas posses, independentemente de serem ilegais ou não, de acordo com os termos da Lei, foram reconhecidas e tornaram-se propriedade particular, registradas e reconhecidas". ${ }^{5}$ Desta forma: "No caso das posses ilegais, quando isso acontecia, elas mudavam de condição, uma vez que recebiam a chancela do Estado, e os invasores passavam a ser legítimos proprietários das terras que invadiam". Assim, ganha relevo o fato das requisições na Amazônia tenderem a buscar regularizar posses previamente estabelecidas através da compra das áreas ocupadas. 0 fato da Diretoria da Agricultura ter tendido a deferir a venda das áreas já possuídas pelos solicitantes tem muito a dizer sobre como esta repartição favoreceu determinados agentes no processo de legitimação de posses irregulares na Amazônia.

A legalização de posses irregulares por meio de alienação de terras devolutas é extremamente coerente com a história de ocupação da região amazônica. Diferentes estudiosos têm demonstrado a posse como principal forma de aquisição de terras nesta região. Maria José dos Santos e José Helder Benatti concordam que a "posse simples" realizada por particulares foi a forma por excelência de ocupação desta região. ${ }^{6}$ De acordo com Santos,

\footnotetext{
${ }^{4}$ MOTTA, Márcia Menendes. Nas fronteiras do poder: conflito e direito à terra no Brasil do século XIX. Niterói, RJ: Arquivo Público do Estado do Rio de Janeiro, 1998, p. 13-31; 119-189.

${ }^{5}$ SILVA, Marcio Antônio Both da. Lei de Terras de 1850: lições sobre os efeitos e os resultados de não se condenar "uma quinta parte da atual população agrícola". Revista Brasileira de História, São Paulo, 2015, p. 15.

6 SANTOS, Maria José. Arranjos, Lei e Consolidação do Império: Aplicação da Lei das Terras e Apropriação das Fazendas Nacionais do Rio Branco (1830-1880). 2018. Tese (Doutorado em História) Departamento de História, Universidade Federal do Pará, Belém, p. 94-96; 179; BENATTI, José Éder. Direito de Propriedade e Proteção Ambiental no Brasil Apropriação e o Uso dos Recursos Naturais do Imóvel Rural. 2003. Tese (Doutorado em Ciências: Desenvolvimento Socioambiental) - Programa de Pósgraduação em Desenvolvimento Sustentável do Trópico Úmido, Núcleo de Altos Estudos Amazônicos, Universidade Federal do Pará, Belém, p. 10-38.
} 
"novos sujeitos sociais - degredados, militares e servidores do Estado - se tornaram detentores de extensos territórios, sem obterem títulos ou cartas de sesmarias, ocorrendo uma posse simples". ${ }^{7}$ Para ela, "O período que vai de 1790-1860 foi o de maior expansão das posses livres, sem cartas de sesmarias, ou outras formas de concessão". ${ }^{8}$ Santos, Barbara Weinstein e Antônio Loureiro concordam que a Lei de Terras de 1850 não regularizou a estrutura fundiária local, diferente do previsto em alguns de seus dispositivos. ${ }^{9}$ Fora isso, a década de 1880 foi aquela na qual Loureiro percebe um crescimento do montante de regularizações na região, indicando, contudo, que "o total de títulos emitidos ainda representava um total baixo comparado à quantidade de posses existentes". ${ }^{10}$ Neste sentido, chama atenção o fato dos pedidos de compra de terra na Amazônia encontrados estarem todos exatamente nesta década. Isto indica que estes pedidos visavam exatamente converter posses irregulares em propriedades legitimadas. O fato de a Diretoria ter priorizado os requisitantes com posse sobre a terra pedida indica também que as próprias instâncias governamentais corroboraram com uma aplicação frouxa da Lei de Terras de 1850 na região, de forma a favorecer estes sujeitos interessados em legitimar suas possessões irregulares.

Machado de Assis escreveu "concordo" seis vezes nestes autos, assumindo o posicionamento seus colegas. ${ }^{11}$ Somente em três requisições de terras no Amazonas, ele acrescentou alguma informação após concordar. ${ }^{12}$ As manifestações tímidas ou burocráticas de Machado nestes processos talvez resultassem de sua posição enquanto chefe da repartição ou pode ter sido uma estratégia de posicionamento dentro das relações sociais daquele campo institucional. O fato é que no quesito da economia das palavras, seus discursos não diferiram muito dos chefes de outras seções ministeriais. Encontramos outros chefes se posicionando da mesma forma em outros processos. Os funcionários da Secretaria da Agricultura não eram concursados. Eles dependiam de manter boas interações políticas com seus colegas e superiores. Neste sentido, talvez fosse mais sábio manter boas relações com os seus colegas, discordando o mínimo possível e omitindo o máximo possível suas opiniões. Ou talvez fosse só a prática daquele cargo ministerial.

Esta postura de Machado de Assis no campo ministerial destoou de seus deboches literários com relação à realidade agrária. No conto "Na Arca: três capítulos (inéditos) das

\footnotetext{
7 SANTOS, Maria José. Arranjos, Lei e... Op. cit., p. 94.

${ }^{8}$ Ibidem, p. 96.

9 Idem; LOUREIRO, Antônio. O Amazonas na época Imperial. Manaus: Valer, 2007, p. 169-192; WEINSTEIN, Bárbara. A Borracha na Amazônia: Expansão e Decadência. São Paulo: Hucitec, 1993, p. 6566.

${ }^{10}$ Idem, p. 169-173.

${ }^{11}$ Arquivo Nacional - Rio de Janeiro (AN-RJ). Ministério da Agricultura, Diretoria da Agricultura, $2^{a}$ Seção, Seção de Guarda Codes, not. 5F 602; AN-RJ. Ministério da Agricultura, Diretoria da Agricultura, 2a Seção, Seção de Guarda Codes, not. 5F 291; MOTTA, Maximino José. Solicitação de compra de terras devolutas em Manaus. In: Coleção Machado de Assis. Acervo da Fundação Casa de Rui Barbosa. Disponível em: www.docvirt.com/DocReader.net/DocReader.aspx?bib=MachadoAssis\&PagFis=1745. Acesso em: $18 \mathrm{fev}$. 2019.

${ }^{12}$ AN-RJ. Ministério da Agricultura, Diretoria da Agricultura, 2a Seção, Seção de Guarda Codes, not. 5F 602.
} 
gênesis", o escritor brincou com a percepção dos potentados rurais sobre a propriedade. Neste texto, publicado em 1878 no jornal O Cruzeiro, sob pseudônimo Eleazar, o autor realiza uma paródia bíblica na qual os filhos de Noé disputam os territórios submersos pelo dilúvio antes de descerem da arca. O tempo todo no texto, as personagens representam a si próprios como legítimos proprietários de terras desconhecidas por eles e aos seus interlocutores na disputa pelos limites fundiários como invasores. Sidney Chalhoub, em Machado de Assis historiador, apresenta também a galhofa do literato para com a percepção senhorial da propriedade através de um trecho do romance Memória Póstumas de Brás Cubas. ${ }^{13} \mathrm{O}$ conto foi publicado sob pseudônimo. O Romance foi escrito em momento no qual a posição de Machado de Assis no campo literário estava consolidada. O cargo nas agências ministeriais, de outro lado, não possuía estabilidade e representava a maior fonte de renda de Machado de Assis (450\$000 réis mensais). Talvez, isto tenha contribuído para uma maior moderação na atuação dele neste campo. Difícil saber ao certo. Porém analisar as decisões da Diretoria da Agricultura pode nos ajudar a perceber os contornos do campo institucional no qual ele atuou. As ações dos sereshumanos possuem relações com a dinâmica social, embora não sejam completamente determinadas por elas. Neste sentido, o contexto talvez nos ajude a entender por tabela a personagem.

\section{Os casos deferidos}

Encontramos cinco casos deferidos pela Diretoria de Agricultura. A primeira demanda autorizada foi realizada pelo comerciante Henrique Ferreira Pena de Azevedo, em junho de 1887, com o intuito da criação de gado. Ele solicitava o terreno de 1500 hectares localizado em Manaus, nas proximidades do igarapé do Paracumba, na paróquia de Nossa Senhora da Conceição. O território seria "limitado pelo Norte com o Paranamiry da Xiburena e pelo poente com o lago da Paracumba até a margem direita do Paraná do lago Janaudry". ${ }^{14} \mathrm{O}$ autor da requisição anunciava ainda Sabino Augusto Kany como confrontante. Sua petição argumentava o fato de ele "já ter estabelecido nesse lugar fazenda de criação de gado e feito diversas benfeitorias". Em seu favor, a Tesouraria da Fazenda informava não ter alienado previamente aquela área e o município atestava tratar-se de terra devoluta . A presidência da província corroborava ainda com o seu pedido, afirmando que "o requerente é comerciante matriculado e faz parte da firma comercial de Ferreira Pena \& Compa desta praça, pelo que está no caso de aproveitar o terreno [...] e pagar o valor do mesmo". Neste sentido, estavam presentes a posse prévia e a capacidade para o cultivo, dois elementos tradicionalmente importantes para a concessão de terras no período colonial.

${ }^{13}$ CHALHOUB, Sidney. Machado de Assis Historiador. São Paulo: Companhia das Letras, 2003, p. 75.

${ }^{14}$ AN-RJ. Ministério da Agricultura, Diretoria da Agricultura, 2a Seção, Seção de Guarda Codes, not. 5F 602. 
A Presidência da província informava ainda que tais terras não estavam compreendidas "nas zonas privilegiadas das estradas de ferro", podendo ser alienadas. Reclamava, entretanto, a respeito da área pedida ser superior ao máximo, de 400 hectares, permitido, pelo Aviso de 5 de novembro de 1887, com relação às terras destinadas para criação. Mas, isto poderia ser contornado para a presidência, pois afirmava: "o suplicante pode ser atendido de acordo com o parecer da Presidência, reduzindo-se a área pedida a 400 hectares". ${ }^{15}$

O documento da presidência foi assinado pelo comendador Francisco Antônio Pimenta Bueno, o Marquês de São Vicente. Tratava-se de um engenheiro, diplomata, magistrado e militar que ocupara a posição de gerente da Amazon Steam Navigation Company. ${ }^{16}$ Ele também exercera, em 1848, o cargo de ministro da justiça. ${ }^{17}$ Atuou como presidente do Maranhão e do Rio Grande do Sul, como funcionário e ministro do ministério dos negócios estrangeiros, bem como no cargo de Senador. Transitou do partido liberal ao conservador. Escreveu livros na área do direito processual civil e constitucional. Em 1833, foi eleito conselheiro da província de São Paulo. Naquele momento, ocupava o cargo de presidente e era membro do partido conservador. No livro Indústria Extrativa. A Borracha, considerações por M. A. Pimenta Bueno, publicado em 1882, questionava o que concebia como ineficácia da Lei de Terras de 1850 no território amazônico. ${ }^{18}$ Para ele, a Lei de Terras de 1850 causaria uma certa dificuldade para as terras amazônicas adquirirem valor monetário. ${ }^{19}$ Esta norma estabelecera um valor idêntico para diferentes províncias venderem terras devolutas. ${ }^{20}$ Isto, ao seu ver, seria um absurdo. Na sua concepção, no Pará e no Amazonas, a terra valeria pouco e, por isso, o preço pré-estabelecido não era eficaz para essa localidade. Era necessário vender terrenos por preço menor do que o legalmente estabelecido. A dificuldade de alienar o território pelo valor tabelado causaria, de acordo com ele, o predomínio de um extrativismo itinerante. Pimenta Bueno era um crítico do extrativismo amazônico, sobretudo de suas técnicas, e, ao mesmo tempo, atiçava o governo a estimular a produção agrícola. ${ }^{21}$ Ele não era o único, pois diferentes intelectuais daquela localidade representavam negativamente os costumes proprietários e as formas de vida dos extrativistas e das populações nativas. ${ }^{22}$ Ao seu ver, como os extrativistas não se considerariam donos das terras, eles pouco se importariam com a preservação desta. ${ }^{23} \mathrm{Em}$ sua concepção, o deslocamento populacional dos

\footnotetext{
${ }^{15}$ AN-RJ. Ministério da Agricultura, Diretoria da Agricultura, 2a Seção, Seção de Guarda Codes, not. 5F 602.

${ }^{16}$ NUNES, Francivaldo Alves. O "Valor" das terras amazônicas no século XIX: questões sobre agricultura e extrativismo. SÆECULUM - Revista de história, João Pessoa, n. 26, jan.-jun. 2012, p. 92.

17 SISON, S. A (org.). Galeria dos brasileiros ilustres. Brasília: Senado Federal, 1999, p. 59.

18 NUNES, Francivaldo Alves. O "Valor" das terras... Op. cit., p. 96.

${ }^{19}$ Ibidem, p. 94.

${ }^{20}$ Ibidem, p. 96.

21 BUENO, Manoel Antônio Pimenta. Indústria Extrativa. A Borracha, considerações por M. A. Pimenta Bueno. Belém: Typ. de Francisco da Costa Júnior, 1882.

22 NUNES, Francivaldo Alves. O "Valor" das terras... Op. cit.

${ }^{23}$ Ibidem, p. 96-97.
} 
extrativistas desta região impediria uma ocupação regular do solo e, assim, a aquisição de valor econômico da parte deste. Para Pimenta Bueno, preciso colocar fim na "a vida ambulante das populações do interior da província". ${ }^{24}$ Tratava-se de uma concepção para a qual a propriedade privada e absoluta era encarada como progresso, enquanto as formas costumeiras de acesso à terra eram percebidas como atrasadas. Suas críticas à legislação agrária buscavam enquadrar os costumes territoriais dos grupos extrativistas nos moldes liberais. Neste sentido, não é de estranhar que Pimenta Bueno aprovasse a venda de terras já ocupadas. Isto legalizaria posses ilegais, mas resultaria na privatização e demarcação daquele território.

O ministro João Lins Vieira de Cansanção de Sinimbu, no relatório de 1878, também defendeu o estabelecimento de preços mais baixos para as terras situadas distante dos mercados. ${ }^{25}$ Ele era um fazendeiro de Alagoas que integrava a ala tradicionalista do partido liberal. ${ }^{26}$ Segundo Angela Alonso, seu gabinete foi "inclinado antes para os senhores que para os escravos". ${ }^{27}$ Com relação a questão agrária, Sinimbu propôs modificar a Lei de Terras de 1850 , nomeando uma comissão de reforma desta legislação, na qual estava presente Machado de Assis. Sinimbu propunha "temperar o rigor do direito estabelecido com relação às posses posteriores ao [...] Regulamento de 1854, nas quais existirem lavouras ou outras benfeitorias". Para ele, "aos posseiros em tais condições", deveria "ser concedido, não só o direito de legitimação, mediante o pagamento [...], senão o de efetuar este em prestações anuais, ou de haver aquelas por aforamento". ${ }^{28}$ Neste sentido, ele reafirmava a importância do costume da posse e a relevância do cultivo.

No processo em tela, Machado de Assis apenas escreveu, no dia 9 de agosto de 1888, a palavra "concordo", referindo-se ao parecer favorável emitido na mesma data pelo Segundo Oficial da Diretoria da Agricultura Francisco de Paula Barros. ${ }^{29}$ Ambos os funcionários aceitaram a venda das terras desde que adequado o tamanho fosse adequado à extensão máxima definida pelo Aviso de 5 de novembro de 1887. Encaminhado ao gabinete ministerial, por fim seria adicionado aos autos, em 5 de setembro de 1888, o despacho final: "Autoriza-se a venda". ${ }^{30}$

O segundo pedido autorizado pelo ministério foi iniciado no dia 8 de agosto de 1888 . Nesta data, o "empregado público" e "tenente coronel" Francisco Ferreira de Lima Bacury

${ }^{24}$ BUENO, Manoel Antônio Pimenta. Indústria Extrativa... Op. cit. Apud NUNES, Francivaldo Alves. O "Valor" das terras... Op. cit., p. 96.

${ }^{25}$ SINIMBU, João Lins Vieira C. de. Relatório do Ano de 1877 apresentado Assembleia Geral Legislativa na primeira sessão da 17 a legislatura. Rio de Janeiro: Imprensa Nacional, 1877, p. 35-38. Disponível em: http://brazil.crl.edu. Acesso em: 10 out. 2019.

${ }^{26}$ ALONSO, Angela. Flores, Votos e Balas: O movimento abolicionista brasileiro (1868-88). São Paulo: Companhia das Leras, 2015, p. 120-121.

27 Ibidem, p. 120-121.

${ }^{28}$ SINIMBU, João Lins Vieira C. de. Relatório do Ano... Op. cit., p. 35-38.

${ }^{29}$ AN-RJ. Ministério da Agricultura, Diretoria da Agricultura, $2^{a}$ Seção, Seção de Guarda Codes, not. 5F 602.

${ }^{30}$ Idem. 
solicitara por compra 0,147 hectares de terras, localizados na capital do Amazonas, mais especificamente na Paróquia de Nossa Senhora dos Remédios. ${ }^{31}$ Ele anunciava como confrontantes, ao norte, as terras apossadas por Evaristo José Joaquim Puccú, pelo Sul, Clarinda da Cruz Barbosa, por leste e oeste respectivamente uma rua e um igarapé, ambos chamados de Manaus. Afirmava ter a intenção de edificar o referido terreno. Assim, como no requerimento anterior, o argumento da posse prévia também foi utilizado por ele, pois pretendia "legalizar a posse que tem sobre um terreno à margem direito do igarapé de Manaus". ${ }^{32}$

O Segundo Oficial da Diretoria da Agricultura, chamado Francisco de Paula Barros, escreveu um parecer no dia 22 de novembro de 1888 propondo o deferimento desta demanda. Este funcionário era um negociante, poeta, teatrólogo, autor de compêndios de física e oficial da marinha nascido no Ceará. Em seu parecer, ele concordava parcialmente com a Inspetoria de Terras, divergindo desta repartição somente com relação ao preço da venda. Machado de Assis apenas se posicionou um dia depois de seu colega, afirmando: "Parece-me indispensável ouvir a presidência da província, que nada absolutamente disse, em relação ao mérito do pedido, nem quanto ao preço". ${ }^{33}$ Esta exigência gerou uma longa troca de cartas envolvendo a Tesouraria da Fazenda, a presidência da província do Amazonas e a Diretoria de Agricultura. No dia 10 de janeiro de 1889, o presidente Joaquim Cardoso de Andrade afirmou em documento dirigido ao ministério: "o suplicante está no caso de edificar o terreno que pretende e sujeitar-se a pagar o preço máximo da lei". ${ }^{34}$ Outra vez, uma autoridade pública afirmava a importância da capacidade de aproveitar a área solicitada como requisito para a aprovação da alienação. Mesmo a Lei de Terras de 1850 buscando sacralizar como propriedade individual e absoluta as terras compradas, as autoridades e alguns dispositivos desta norma jurídica continuavam a exigir dos compradores a capacidade de realizar a posse e de aproveitar economicamente o território. Retomavam, assim, de certo modo, a exigência presente no regime das sesmarias para o súdito receber concessões régias de terras.

A Presidência da província afirmava ainda: "Julgo de meu dever dizer a V. Excia que me parece preferível a venda definitiva de terras em tais condições do que estarem elas na posse de particulares, com manifesto prejuízo do Estado e flagrante infração da lei". ${ }^{35} \mathrm{Na}$ prática, argumentava em favor da legalização de posses irregulares por meio da venda. Ao mesmo tempo em que as autoridades valorizavam a posse prévia dos solicitantes como critério para autorizar a alienação de terras, eles recriminavam os posseiros, sobretudo os que não pudessem legalizar suas posses por meio da compra. Como demonstra Márcia Motta, geralmente eram os pequenos posseiros aqueles que cotidianamente sofriam com o rótulo de

\footnotetext{
${ }^{31}$ AN-RJ. Ministério da Agricultura, Diretoria da Agricultura, 2a Seção, Seção de Guarda Codes, not. 5F 291.

${ }^{32}$ Idem.

${ }^{33}$ Idem.

${ }^{34}$ Idem.

${ }^{35}$ Idem
} 
invasor. ${ }^{36}$ Ademais, a venda das terras, não a regularização fundiária, era apontada pela presidência como solução para a constante apropriação irregular dos domínios públicos. Assim, a preocupação não era em reformar a estrutura fundiária de forma a combater o descontrole estatal sobre o território e, consequentemente, assegurar a proteção das áreas devolutas, florestais, indígenas e de outros indivíduos. Tratava-se de propor a transferência das terras para o domínio particular e, com elas, a responsabilidade de demarcar os limites territoriais. Os compradores de terras devolutas se responsabilizavam por pagar a medição e legitimação. Ao Estado, restaria somente o valor pecuniário dos domínios transferidos. Eram recorrentes as reivindicações atendidas de adiamento dos prazos de medição das terras compradas pelos particulares. Neste sentido, por esta proposta, nem a regularização daquelas terras estaria assegurada.

O terceiro caso deferido pelo Ministério de Agricultura, Comércio e Obras Públicas foi fruto da demanda de Fabiano José da Gama. Em 1888, ele pediu "por compra, 100 hectares de terras devolutas, de que está de posse, à margem esquerda do rio Negro, na paróquia de $\mathrm{N}$. Sa. da Conceição de Manaus, no município da Capital". ${ }^{37}$ Em seu favor, a câmara municipal e a presidência da província alegaram respectivamente estarem os mesmos terrenos fora do patrimônio da municipalidade e da área reservada para estradas de ferro. O governo local afirmava ainda não existirem outros posseiros naquela região. O Inspetor Geral Francisco de Barros e Accioli de Vasconcellos apresentou, por um lado, o fato negativo das "terras pedidas à margem de um rio navegável". ${ }^{38}$ O Aviso de 5 de novembro de 1887, em sua terceira cláusula, determinava que estas áreas deveriam ser "reservadas para a formação de núcleos coloniais". ${ }^{39}$ Entretanto, defendeu o deferimento, afirmando: "Todavia, atendendo-se às condições especiais daquela província, ao seu grande território, pouca população e a diminuta imigração que aflui para ali, penso que poderá atender se ao suplicante". ${ }^{40}$ Para o inspetor, as condições especiais daquela província fariam dela pouco atraente para a fundação de núcleos coloniais. Por isso, poderia ser realizada a doação na beira do rio Negro, indo contra a determinação do referido aviso. Não era necessário reservar para a colonização. O inspetor Accioli era filho de proprietários alagoanos e tenente coronel honorário. Suas informações sobre a colonização deveriam ser bastante valorizadas, pois em 1884 havia publicado um manual chamado Guia do imigrante para o império do Brasil. ${ }^{41} \mathrm{~A}$ orientação de não reservar terras para a colonização combinava com a prática de alguns agentes Estado Imperial de

\footnotetext{
36 MOTTA, Márcia. Posseiros no Oitocentos e a Construção do Mito Invasor no Brasil (1822-1850). In: ZARTH, Paulo; MOTTA, Márcia (orgs.). Formas de resistência camponesa: visibilidade e diversidade de conflitos ao longo da história. São Paulo: Ed. UNESP, 2008, p. 100.

37 AN-RJ. Ministério da Agricultura, Diretoria da Agricultura, 2a Seção, Seção de Guarda Codes, not. 5F 602.

38 Idem.

${ }^{39}$ Idem.

40 Idem.

41 VASCONCELLOS, Francisco de Barros e Accioli. Guia do emigrante para o Império do Brasil. Rio de Janeiro: Typographia Nacional, 1884.
} 
priorizar outras províncias na alocação dos imigrantes. ${ }^{42}$ Existiram naquele momento debates sobre a fundação de colônias na região amazônica, havendo, inclusive, "insatisfação de setores da sociedade com as ações promovidas pela presidência do Pará no sentido de promover a colonização da região". ${ }^{43}$

Tanto João Capistrano do Amaral, Primeiro Oficial da Diretoria da Agricultura, quanto Machado de Assis concordaram com o parecer da inspetoria no dia 14 de dezembro de 1888. Eles apenas solicitaram uma informação. Para Amaral, "Antes de qualquer resolução, pareceme conveniente verificar [...] se o suplicante dispõe de meios para cultivar as terras". ${ }^{44} \mathrm{O}$ chefe da seção apenas subscreveu "Concordo", referindo-se ao parecer do oficial sob seu comando. Por fim, a venda foi deferida. ${ }^{45}$

A requisição de Florindo Rodrigues Vieira, "cidadão brasileiro e morador no lugar denominado Forte de Veneza", também mencionava a existência de posse anterior, em sua petição inicial datada de 10 de agosto de 1888 . Ele pretendia realizar "cultivo da goma elástica" e informava, enviando documentos para comprovar sua afirmação, ter "posse desse lugar há mais de dois anos". ${ }^{46}$ Tratava-se de um lote de terras devolutas denominado "Sobradinho" e localizado "à margem esquerda do Rio Purús", compreendendo a área de 1000 hectares. O requerente declarava os seguintes confrontantes: "as terras do major Jacyntho Correia da Silva Bottinelli, [...] os seringais pertencentes aos comerciantes desta praça F. R. Vieira \& Companhia, pelos lados do fundo com propriedade de Manoel Monteiro Pantoja e Capitão Raimundo Gomes de Araújo". ${ }^{47}$ O solicitante, ainda, argumentava ter uma posse de boa-fé, afirmando que "comprou essas terras a Manoel Carlos de Sabará" sem saber se tratar de uma venda nula, "por não constar que o vendedor fosse proprietário das terras das terras". 48

Sobre este pedido, o oficial da Diretoria da agricultura João Capistrano do Amaral escreveu em outubro de 1888: "Parece-me que, antes de qualquer resolução, convém devolver o requerimento à Presidência para que preste os esclarecimentos constantes da cláusula $3^{a}$ da circular de 5 de novembro de 1887". ${ }^{49}$ Esta cláusula determinava que as terras no entorno de rios navegáveis deveriam ser reservadas à colonização. Machado de Assis, como de costume, limitou-se a subscrever "concordo", no dia 31 daquele mês, referindo-se ao

42 COELHO, Ana Carolina de Abreu. Barão de Marajó: um intelectual e político entre a Amazônia e a Europa (1855-1906). 2015. Tese (Doutorado em História) - Departamento de História, Universidade Federal do Pará, Belém, p. 192-193.

43 NUNES, Francivaldo Alves. Agricultura e civilização no Pará Imperial: terra, matas e povoamento. Histórica: Revista Eletrônica do Arquivo Público do Estado de São Paulo, São Paulo, n. 36, 2009, p. 3-4.

${ }^{44}$ AN-RJ. Ministério da Agricultura, Diretoria da Agricultura, $2^{a}$ Seção, Seção de Guarda Codes, not. 5F 602.

${ }^{45}$ Idem.

${ }^{46}$ AN-RJ. Ministério da Agricultura, Diretoria da Agricultura, $2^{a}$ Seção, Seção de Guarda Codes, not. 5F 291.

${ }^{47}$ Idem.

${ }^{48}$ Idem.

${ }^{49}$ Idem. 
parecer de seu colega. A presidência da província, por sua vez, respondeu no dia 11 de janeiro de 1889:

Informando tal pretensão, cabe-me dizer que o dito terreno está compreendido na hipótese $3^{a}$ do Aviso de 5 de novembro de 1887, mas isso não deve servir de pretexto a não concessão do terreno, visto achar-se muito longe de todos os centros populosos. E quando mesmo nas suas proximidades algum núcleo colonial, que se desenvolva, o governo dispõe de meios para a desapropriação. ${ }^{50}$

Assumindo não ser fácil estabelecer núcleos coloniais naquela região, o presidente da província assinou o documento defendendo a alienação daqueles terrenos, não obstante estar localizado na beira de rio navegável. Após relatar o posicionamento da presidência do Amazonas, no dia 29 de março de 1889, o oficial da diretoria Paula Barros defendeu em seu parecer: "Opino, à vista das informações, pela concessão. A cláusula $3^{a}$ do citado Aviso conviria não ser entendida com as províncias do Amazonas, Pará, Mato Grosso, Goiás, onde não é fácil a formação de núcleos coloniais, estrangeiros sobretudo". ${ }^{51} \mathrm{O}$ caso foi, enfim, aprovado pelo ministério. Pela segunda vez, a diretoria relativizava o impedimento de doações nas bordas dos rios navegáveis para o Amazonas. No dia 27 de agosto de 1888, a presidência da província encaminhara para o ministério a solicitação de Maximino José da Motta. Trata-se do quinto caso deferido pelo ministério. O requerente pedia "por compra um terreno a margem direita do igarapé de Manaus, paróquia de N. S. dos Remédios com área de 826,5 braças", tendo como finalidade a edificação. ${ }^{52}$ Estas terras possuíam como confrontantes as ruas Manaus, 9 de novembro e General Miranda Reis, além do referido igarapé. Sobre esta demanda, o Inspetor Geral Francisco de Barros e Accioli de Vasconcelos escreveu em seu parecer:

Cabe-me informar à V. Ex cia que o suplicante pode ser atendido, tendo-se em vista a pequena área do terreno que pede, parecendo, todavia, não ser conveniente a alienação das terras devolutas existentes numa capital que tende a desenvolver-se, e pode mais tarde carecer delas para o seu desenvolvimento ou para qualquer melhoramento de utilidade pública. ${ }^{53}$

Para ele, a venda não deveria ser realizada, pois região onde ficavam tenderia ao desenvolvimento e, por isso, o governo poderia precisar delas no futuro para realizar obras de infraestrutura. O limite não ultrapassava o disposto na Circular de 5 de novembro de 1887, mas, para a inspetoria, existiriam outras razões para indeferir o pedido. A presidência da província anunciava que a terra requerida não possuía impedimentos legais para ser alienada. O parecer de Paula Barros, funcionário da Diretoria da Agricultura, divergiu da proposta de decisão proveniente da inspetoria. Para ele, "Se se for esperar que a imensa província do Amazonas venha a carecer de pequeninas porções de terra para desenvolver-se, mal irá. Tendo deve ela esperar do desenvolvimento particular, e a edificação

${ }^{50}$ AN-RJ. Ministério da Agricultura, Diretoria da Agricultura, 2a Seção, Seção de Guarda Codes, not. 5F 291.

${ }^{51}$ Idem.

52 MOTTA, Maximino José. Solicitação de compra... Op. cit.

${ }^{53}$ Ibidem, p. 4. 
é um de seus maiores fatores de progresso". ${ }^{54}$ Diferente de Accioli de Vasconcelos, ele não considerava importante reservar a terra para um momento futuro quando a província viesse a se desenvolver. Defendendo uma perspectiva liberal para a qual o desenvolvimento resultaria de ações individuais, o oficial da diretoria propôs deferir a venda para o suplicante edificar como um elemento motivador deste mesmo progresso. No dia 11 de dezembro de 1888, Machado de Assis subscreveu ao parecer de seu colega: "Concordo. Sobe projeto de aviso". 55

Em seu parecer, a inspetoria descrevia o pedido do autor da seguinte maneira: "Maximino José da Motta pede para legalizar a posse de um terreno". Esta repartição também considerava que, segundo as disposições legais, "o suplicante pode ser atendido". ${ }^{56}$ Não obstante seu pedido estar em acordo com a legislação e ele ter a posse prévia, surpreende o inspetor ser contra à venda. Ele já estava possuindo a área demandada. Mas corresponde às expectativas o fato de os dois funcionários da Diretoria da Agricultura contrariarem esta proposta de negativa, recomendando a venda. A posição de Machado de Assis de chefe da seção permitiu que ele batesse o martelo, encaminhando ao ministro ao projeto de Aviso favorável ao solicitante. O caso, assim, confluiu sendo deferido.

Outrossim, chama atenção o fato das cinco requisições de terras deferidas na província do Amazonas terem utilizado como argumento a existência da posse prévia e da capacidade para utilizar economicamente a área almejada. Cabe lembrar que tais argumentos não foram somente proferidos pelos particulares interessados na compra, mas também pelos pareceres das autoridades responsáveis por analisar o caso. Neste sentido, é evidente a continuidade da importância de elementos característicos do regime proprietário anterior à Lei de 1850 , como a posse e a capacidade de utilizar economicamente o bem imóvel. A persistência destes costumes lembra ao historiador que a transformação na relação entre homens e bens não ocorre por decreto, lei ou outro dispositivo jurídico proveniente do governo central. Ainda que a Lei de Terras de 1850 buscasse sacralizar a propriedade adquirida pela compra, as autoridades deste mesmo poder centralizado que a aplicavam continuavam a utilizar os critérios do regime anterior para deferirem as solicitações de compra de terras devolutas.

A própria Lei de 1850 priorizava, no artigo 150, os indivíduos com capacidade de aproveitar as terras e com posse nas terras contíguas: "Os possuidores de terra de cultura e criação [...] terão preferência na compra das terras devolutas que Ihes forem contiguas, contanto que mostrem [...] que tem os meios necessários para aproveitá-las". Entretanto, este dispositivo se referia aos possuidores de terras contíguas àquelas desejadas. Os casos aqui expostos revelam uma outra situação, os solicitantes buscavam comprar do governo áreas já ocupadas para legitimar posses irregulares. Fosse a Lei de 1850 seguida à risca, estes casos deveriam ser compreendidos no definido pelo artigo $5^{\circ} \S 2^{\circ}$ desta norma: "As posses em circunstâncias de serem legitimadas, que se acharem em [...] concessões do Governo [...] só darão direito à indemnização pelas benfeitorias". Poderiam ainda ser regidas pelo $2^{\circ}$ artigo: "Os que se apossarem de terras devolutas [...], e nelas derribarem matos ou thes puserem fogo, serão obrigados a despejo [...] e de mais sofrerão a pena de dois a seis meses do prisão e multa de $100 \$ "{ }^{57}$

Não é difícil assim perceber uma certa condescendência das autoridades com os posseiros com capacidade para cultivarem as áreas demandadas. A nova legislação continuava sendo lida com a lente da bagagem cultural (ou legal) associada aos padrões de propriedade do sistema jurídico anterior. As

\footnotetext{
54 MOTTA, Maximino José. Solicitação de compra... Op. cit., p. 2.

${ }^{55}$ Ibidem, p. 3.

${ }^{56}$ Ibidem, p. 4.

${ }^{57}$ BRASIL. Lei 601 de 18 de setembro de 1850. In: Coleção das leis do Império do Brasil. Vol. 1. Parte 1. Rio de Janeiro: Tipografia Nacional, 1851.
} 
autoridades entendiam o pequeno posseiro como invasor, enquanto o tenente ou o comerciante (com capacidade para o cultivo) teria uma posse digna de ser legitimada através da compra das terras apropriadas irregularmente. Esta diferenciação estava bastante associada à lógica do privilégio. Também apresentava traços do regime de sesmarias, pois neste sistema pretérito exigia-se a capacidade de cultivo - geralmente revelada na propriedade de cativos - para aprovar a concessão régia para os requerentes.

Embora a venda começasse a ser sacralizada, no XIX, como forma hegemonicamente aceita de adquirir propriedade, as solicitações de venda de terras devolutas e os critérios para o deferimento das requisições lembravam muito a fórmula do regime das sesmarias. Além disso, os requerentes continuavam, nos discursos de suas petições iniciais, solicitando aos ocupantes do trono, como se pedissem uma graça. A resposta à requisição, entretanto, dependia da repartição de terras públicas, do legislativo provincial e do ministério da agricultura. Os cargos dos funcionários deste último órgão iniciavam a serem ocupados pela nomeação do imperador. Ele escolhia o presidente do conselho dos ministros. Este, por sua vez, nomeava os titulares da pasta que decidiam os cargos dos diretores e estes dos chefes, oficiais, amanuenses, praticantes, porteiros e contínuos de cada seção de sua Diretoria. Neste sentido, embora as requisições se dirigissem ao monarca, elas eram analisadas por funcionários governamentais inseridos nas regras do sistema representativo daquele período.

\section{Casos indeferidos}

Um dos processos indeferidos foi iniciado em 3 de outubro de 1888 por petição do "extrator de goma elástica e comerciante" Hilário Francisco Alvares. Ele solicitava 1519 hectares de terra "para a extração de goma elástica, a margem esquerda do Rio Purus, no lugar denominado "Espírito Santo", distrito policial de Hyntanaham, termo e munícipio da Vila da Lábrea". ${ }^{58}$ A Câmara Municipal foi favorável ao seu pleito, anunciando que a área solicitada não fazia parte de seu patrimônio. A Inspetoria Geral de Terras e Colonização também defendeu deferimento, condicionando, entretanto, sua posição à adequação do tamanho a ser vendido ao máximo permitido pela Circular de 5 de novembro de 1887, 1000 hectares. Também informou que seria "o concessionário obrigado a renovar e conservar os seringais sob pena de perder a concessão e as benfeitorias". ${ }^{59}$ Este é um dos poucos casos em que Machado de Assis discorda de seus interlocutores no processo. Para ele, o fato do suplicante pedir mais do que o permitido deveria resultar no indeferimento e, caso o requerente mantivesse o seu interesse, deveria requerer novamente a medida legalmente autorizada.

Após ser indeferido o pedido, Hilário Francisco Alvares demandou a reconsideração do despacho. Neste novo documento, o autor explicava o motivo pelo qual deveria the ser concedido um lote maior do que o disposto no dispositivo jurídico. Em primeiro lugar, explicava elementos da geografia local desconsiderados pela circular: em "mais da metade de sua

${ }^{58}$ AN-RJ. Ministério da Agricultura, Diretoria da Agricultura, 2a Seção, Seção de Guarda Codes, not. 5F 292.

${ }^{59}$ Idem. 
extensão a superfície coberta pela enchente". ${ }^{60}$ De acordo com ele, "no rio Purus dura a enchente desde o mês de outubro até fins de março" e "é justamente aí, nas várzeas, em terras baixas, que se encontram os seringais". ${ }^{61}$ Isto faria destes terrenos "absolutamente impróprios para a lavoura ou criação de gado, e muito menos para a colonização". Pois isso, o requerente defendia que "sendo esses terrenos impróprios para a colonização, é claro que não há vantagem em reservá-los para a formação de núcleos coloniais; e assim ficam excluídos da proibição contida na cláusula $3^{3}$ da circular de 5 de novembro de $1887^{\prime \prime}{ }^{62}$ Argumentava ainda que "a área é apenas metade do máximo de 3.000 hectares, fixado pelo Decreto n. 5655 de 3 de junho de 1874, para a indústria de criação de gado". ${ }^{63}$ Isto seria injusto, pois a criação exigiria "menor espaço do que a de extração da goma elástica". ${ }^{64}$ Continuava com a sua reclamação, argumentando:

A área pedida, que à primeira vista pode parecer muito extensa, não o é para quem, como Vossa Majestade Imperial, conhecendo a indústria extrativa, sabe que as seringueiras não se encontram juntas nas matas, mas sim crescem separadas uma das outras, e às vezes em grande distância; além de que há também igapós, ou terrenos permanentemente alagados, imprestáveis e impróprios para qualquer indústria. ${ }^{65}$

Ele não só questionava o fato da legislação deixar de lado as necessidades e características da extração de borracha na sua região, mais, ao mesmo tempo, apelava para a imagem de sábio do Imperador. Entretanto, sua argumentação seria em vão, pois no dia 16 de janeiro de 1889 seu pedido seria "Indeferido por não estar de acordo (o pedido) com a Circular de 5 de 9 bro de $87 " .{ }^{66}$ Diferente do pedido de comerciante Henrique Ferreira Pena de Azevedo, o dele não teve o tamanho ajustado para o máximo permitido pela Circular de 5 de novembro de 1887. A extensa descrição da especificidade da região das terras demandadas também não foi considerada como uma razão justa para contornar os dispositivos da circular. Em outros casos deferidos, os próprios funcionários da diretoria usaram esses argumentos para driblar a legislação. Mas na requisição de Hilário Francisco Alvares, estas mesmas autoridades recusaram estas justificativas. Salta aos olhos o fato de Hilário Francisco Alvares não ter anunciado posse prévia, diferente do outro que teve solicitação deferida.

A segunda solicitação de compra de terras indeferida recebeu a mesma justificativa para o despacho negativo: o tamanho da área demandada era maior do que o permitido pela legislação. Felippe Joaquim de Souza Filho requereu, em 1888, 1229,76 hectares destinados à

\footnotetext{
60 AN-RJ. Ministério da Agricultura, Diretoria da Agricultura, 2a Seção, Seção de Guarda Codes, not. 5F 292.

${ }^{61}$ Idem.

62 Idem.

${ }^{63}$ Idem.

${ }^{64}$ Idem.

${ }^{65}$ Idem.

${ }^{66}$ Idem.
} 
"lavoura e criação de gado". ${ }^{67}$ Estas estavam localizadas "à margem do rio Negro, na paróquia de N. S. da Conceição de Manaus, município da capital". ${ }^{68}$ A presidência da província argumentara em seu favor, informando que "o terreno pedido está fora das zonas privilegiadas das estradas de ferro". ${ }^{69}$ A Câmara Municipal também apoiara seu pleito. Em nenhum momento do processo aparecem quaisquer menções ao requerente já possuir ou produzir na área. Também não existem, nas fontes, discussões sobre a sua capacidade para executar estas ações. O Inspetor Geral Francisco Barros e Accioli propôs deferir o pedido, doando apenas os 400 hectares permitidos por lei. João Capistrano do Amaral, Primeiro Oficial da Diretoria da Agricultura, entretanto, pensava diferente. Para ele, "Sendo a área pedida superior ao máximo da circular de 5 de novembro de 1887, e proibindo-se a mesma circular a concessão de terras à margem dos rios navegáveis, parece-me que não pode ser atendido o pedido do suplicante". ${ }^{70}$ Machado de Assis, no dia 18 de dezembro de 1888, referendou 0 parecer de seu colega da diretoria:

\begin{abstract}
Concordo. Já tive ocasião de dizer, e ainda ontem o repeti, em papel desta mesma Província, sobre as terras na mesma região, que me não parece boa prática administrativa conceder 400 hectares (máximo da Circ. de 1887) a pessoa que pede $1.229,76$ hect. Não se podendo conceder o que o sup ${ }^{\mathrm{e}}$. requer, penso ser mais curial indeferi-lo dando a razão do indeferimento. $O$ interessado que requeira depois. ${ }^{71}$
\end{abstract}

Mais uma vez, a razão do indeferimento seria o requerente ter solicitado mais do que o permitido pela Circular de 5 de novembro de 1887. Adicionava-se agora a suspeita dele ter incluído na área pretendida as margens do rio Negro. Se o leitor estiver atento, perceberá que o fato das terras solicitadas estarem na beira do rio Negro não foi um impedimento para autorizar a alienação de terrenos para o requerente Fabiano José da Gama. A diferença entre os dois casos era que Fabiano possuía a posse prévia da área demandada por ele. O mesmo pode ser dito com relação à demanda de Florindo Rodrigues Vieira por terras na beira do Purus. Em dois casos, a proibição de doação ribeirinha em rios navegáveis foi relativizada. Somente em um dos três processos, na demanda de Felippe Joaquim de Souza Filho, isto não ocorreu. Não parece ser surpresa perceber que, dentre os três casos, somente no indeferido inexistia posse prévia.

Nesse mesmo processo, o chefe da segunda seção da Diretoria da Agricultura, Machado de Assis, deixava claro ser contrário a adequar o tamanho dos quinhões à Circular, quando a área solicitada fosse maior do que o permitido. Discordava mais uma vez no mesmo assunto com a Inspetoria de Terras e Colonização. Os dois casos recusados pela Diretoria de

\footnotetext{
${ }^{67}$ AN-RJ. Ministério da Agricultura, Diretoria da Agricultura, $2^{a}$ Seção, Seção de Guarda Codes, not. 5F 292.

${ }^{68}$ AN-RJ. Ministério da Agricultura. Diretoria da Agricultura. 2a Seção. Seção de Guarda Codes, not. 5F 602.

${ }^{69}$ Idem.

${ }^{70}$ Idem.

${ }^{71}$ Idem.
} 
Agricultura pediam uma área mais extensa do que o legalmente autorizado. Eles também tinham em comum não mencionar a existência da posse prévia e da capacidade para produzir. A inexistência da posse parece ter motivado a diferença de tratamento entre os demandantes.

\section{Conclusão}

O argumento da posse prévia e da capacidade para o cultivo teve grande importância no interior da Diretoria da Agricultura. Os cinco requerentes cujas requisições foram aprovadas argumentavam informando estarem produzindo ou ocupando nos terrenos devolutos solicitados por compra. Os autores dos processos indeferidos não fizeram o mesmo. As próprias autoridades, em diferentes processos, buscaram evidências da capacidade para o cultivo e davam outras pistas da importância atribuída ao fundamento da posse. Em outras palavras, as autoridades valorizaram as requisições que buscavam legalizar posses por meio da compra de terras e favoreciam solicitantes com recursos para utilizar economicamente estas áreas.

Nos dois casos recusados pela Diretoria, os funcionários argumentavam respectivamente estarem eles na beira de rios navegáveis e o fato dos solicitantes pedirem mais do que o permitido na Circular de 1887. Entretanto, os dispositivos jurídicos utilizados para referendar estas negativas foram relativizados em outros casos deferidos. Na demanda deferida de Fabiano José da Gama, não importou que o Aviso de 5 de novembro de 1887 determinasse que as bordas dos rios navegáveis deveriam ser "reservadas para a formação de núcleos coloniais". ${ }^{72}$ Este princípio foi relativizado. O funcionário da diretoria propôs a relativização da regra: "Opino, à vista das informações, pela concessão. A cláusula $3^{a}$ do citado Aviso conviria não ser entendida com as províncias do Amazonas, Pará, Mato Grosso, Goiás, onde não é fácil a formação de núcleos coloniais, estrangeiros sobretudo". ${ }^{73}$ Hilário Francisco Alvares, de outro lado, recorreu em vão contra o indeferimento de sua solicitação. Ele argumentou afirmando que "sendo esses terrenos impróprios para a colonização, é claro que não há vantagem em reservá-los para a formação de núcleos coloniais; e assim ficam excluídos da proibição contida na cláusula $3^{a}$ da circular de 5 de novembro de $1887^{\prime \prime} .^{74}$ Os seus argumentos eram idênticos àqueles utilizados por Paula Barros para relativizar a legislação em favor de Fabiano José da Gama. O diferencial entre os casos foi a posse prévia do caso deferido. A cláusula do tamanho máximo também foi contornada para o autor que afirmou possuir os terrenos.

\footnotetext{
${ }^{72}$ AN-RJ. Ministério da Agricultura, Diretoria da Agricultura, 2a Seção, Seção de Guarda Codes, not. 5F 602.

${ }^{73}$ AN-RJ. Ministério da Agricultura, Diretoria da Agricultura, 2a Seção, Seção de Guarda Codes, not. 5F 291.

${ }^{74}$ Idem.
} 
Segundo March Bloch, "para grande desespero dos historiadores, os homens não têm o hábito, a cada vez que mudam de costumes, de mudar de vocabulário". ${ }^{75}$ Parafraseando esta assertiva, poderíamos dizer que para grande desespero dos positivistas, os homens não têm o hábito, a cada vez que mudam as leis, de mudar seus costumes jurídicos. Funcionários de cargos administrativos, responsáveis por aplicar a Lei de Terras de 1850 e a Circular de 1887, interpretaram estas normas pelos parâmetros do regime proprietário pretérito. Eles valorizavam a posse prévia para autorizar a venda de terras devolutas, fazendo perpetuar a importância da ocupação do regime das sesmarias. Isto nos apresenta uma visão diferente daquela apresentada por José Murilo de Carvalho segundo a qual a burocracia tentaria aplicar a Lei de Terras de 1850 , enquanto a elite econômica vetaria esta norma na prática. ${ }^{76}$ Márcia Motta já havia apontado que a divisão binária em aplicada/vetada não é suficiente para representar a realização jurídica da legislação. ${ }^{77}$ Esta historiadora aponta como diferentes atores sociais interpretaram a norma para se posicionarem em conflitos jurídicos da época. ${ }^{78}$ Os funcionários da Secretaria de Agricultura também realizaram leituras criativas da legislação. Eles interpretaram-na pressupondo valores do regime das sesmarias.

Machado de Assis foi um dos funcionários da Diretoria de Agricultura que aplicaram a legislação desta forma. Em um caso, ele concordou com o seu colega na assertiva: "Antes de qualquer resolução, parece-me conveniente verificar [...] se o suplicante dispõe de meios para cultivar as terras". ${ }^{79}$ Ele também concordou com 0 indeferimento das solicitações que demandavam área maior do que o permitido. Também escreveu "concordo" em um caso deferido a despeito de solicitar área excessiva. ${ }^{80}$ Machado de Assis criticava a política agrária oitocentista em seus escritos literários. ${ }^{81}$ Entretanto, em seu papel ministerial, ele parece ter acompanhado as decisões que foram colocadas pelos seus colegas. Só divergiu em poucos pontos. Difícil saber o quanto ele concordava de fato com elas. Entretanto, conseguimos perceber quais decisões geralmente a Diretoria tomava. Isto nos permite ter uma noção de como Machado respondia às contingências de seu trabalho como funcionário público. Não por acaso, seus biógrafos tendem a apresenta-lo como funcionário ideal. ${ }^{82}$ Submeter-se às expectativas de seu campo, entretanto, tinha suas consequências.

\footnotetext{
${ }^{75}$ BLOCH, Marc. Apologia da História, ou, O ofício do historiador. Rio de Janeiro: Zahar, 2001, p. 59.

76 CARVALHO, José Murilo de. A Modernização frustrada: A política de terras no Império. Revista Brasileira de História, São Paulo, n. 1, p. 39-57, 1981.

77 MOTTA, Márcia Menendes. Nas fronteiras do poder... Op. cit., p. 61-85; 159-187.

78 Ibidem, p. 159-189.

${ }^{79}$ AN-RJ. Ministério da Agricultura, Diretoria da Agricultura, 2a Seção, Seção de Guarda Codes, not. 5F 602.

${ }^{80}$ Idem.

${ }^{81}$ RODRIGUES, Pedro Parga. A experimentação literária de Machado de Assis e o tema da propriedade da terra no XIX. Revista Cantareira, Niterói (RJ), n. 28, jan.-jul. 2018.

82 MAGALHÃES JUNIOR, R. Vida e Obra de Machado de Assis. Vol. 2: Ascenção. Rio de Janeiro: Civilização Brasileira, 1981, p. 73-85; 205-214.
} 


\section{Referências}

\section{Fontes}

ARQUIVO NACIONAL - RIO DE JANEIRO. Ministério da Agricultura, Diretoria da Agricultura (1873-1890), 2a Seção, Seção de Guarda Codes, notação 1B-55, GIFI. 291.

AN-RJ. Ministério da Agricultura, Diretoria da Agricultura (1873-1890), 2a Seção, Seção de Guarda Codes, notação 1B1-36, GIFI. 291.

AN-RJ. Ministério da Agricultura, Diretoria da Agricultura (1873-1890), 2a Seção, Seção de Guarda Codes, notação 4B-13-14, 174-177, GIFI. 291.

AN-RJ. Ministério da Agricultura, Diretoria da Agricultura (1873-1890), 2a Seção, Seção de Guarda Codes, notação 4I-59, GIFI. 291.

AN-RJ. Ministério da Agricultura, Diretoria da Agricultura (1873-1890), 2a Seção, Seção de Guarda Codes, notação 5B-256, GIFI. 291.

AN-RJ. Ministério da Agricultura, Diretoria da Agricultura (1873-1890), 2a Seção, Seção de Guarda Codes, notação 5F-229, 262, 291-292, 361, 464, 602, 605, GIFI. 291.

AN-RJ. Ministério da Agricultura, Diretoria da Agricultura (1873-1890), 2a Seção, Seção de Guarda Codes, notação 6D-60, GIFI. 291.

BUENO, Manoel Antônio Pimenta. Indústria Extrativa. A Borracha, considerações por M. A. Pimenta Bueno. Belém: Typ. de Francisco da Costa Júnior, 1882.

MOTTA, Maximino José. Solicitação de compra de terras devolutas em Manaus. In: Coleção Machado de Assis. Acervo da Fundação Casa de Rui Barbosa. Disponível em: www.docvirt.com/DocReader.net/DocReader.aspx?bib=MachadoAssis\&PagFis=1745. Acesso em: 18 fev. 2019.

VASCONCELLOS, Francisco de Barros e Accioli. Guia do emigrante para o Império do Brasil. Rio de Janeiro: Tipografia Nacional, 1884.

\section{Bibliografia}

BLOCH, Marc. Apologia da História, ou, O ofício do historiador. Rio de Janeiro: Zahar, 2001.

BENATTI, José Éder. Direito de Propriedade e Proteção Ambiental no Brasil Apropriação e o Uso dos Recursos Naturais do Imóvel Rural. 2003. Tese (Doutorado em Ciências: Desenvolvimento Socioambiental) - Programa de Pós-graduação em Desenvolvimento Sustentável do Trópico Úmido, Núcleo de Altos Estudos Amazônicos, Universidade Federal do Pará, Belém.

CARVALHO, José Murilo de. A Modernização frustrada: A política de terras no Império. Revista Brasileira de História, São Paulo, n. 1, p. 39-57, 1981.

CHALhOUB, Sidney. Machado de Assis Historiador. São Paulo: Companhia das Letras, 2003.

CHALHOUB, Sidney; PEREIRA, Leonardo Afonso de M. (orgs.). A história contada: Capítulos de história social da literatura no Brasil. Rio de Janeiro: Nova Fronteira, 1998.

COELHO, Ana Carolina de Abreu. Barão de Marajó: um intelectual e político entre a Amazônia e a Europa (1855-1906). 2015. Tese (Doutorado em História) - Departamento de História, Universidade Federal do Pará, Belém.

GABLER, Louise. A Secretaria de Estado dos Negócios da Agricultura, Comércio e Obras Públicas e a modernização do Império (1860-1891). Rio de Janeiro: Arquivo Nacional, 2012 
GLEDSON, John. Machado de Assis e a Crise dos 40 anos. Machado de Assis em linha, São Paulo, ano 4, n. 8, dez. 2011.

GROSSI, Paolo. A propriedade e as propriedades na oficina do Historiador. In: História da propriedade \& Outros Ensaios. Rio de Janeiro: Renovar, 2006.

HAZIN, Elizabeth; GUEDES, Paulo. Machado de Assis e a administração pública federal. Brasília: Senado Federal, 2006.

LOUREIRO, Antônio. O Amazonas na época Imperial. Manaus: Valer, 2007.

MACHADO, Paulo Pinheiro; DAROSSI, Flávia Paula. A política de acesso à terra no Brasil Imperial e a compra de terras devolutas no planalto da província de Santa Catarina. Clio: Revista de Pesquisa Histórica do Programa de Pós-Graduação em História da Universidade Federal de Pernambuco, Recife, v. 34, n. 2, 2016.

MAGALHÃES JUNIOR, Raimundo de. Vida e obra de Machado de Assis. Rio de Janeiro: Civilização Brasileira, 1981.

MAGALHÃES JÚNIOR, Raimundo. Machado de Assis funcionário público. Revista do Serviço Público, Brasília, p. 237-248, abr.-jun. 2005.

MOTTA, Márcia Menendes. Nas fronteiras do poder: conflito e direito à terra no Brasil do século XIX. Niterói, RJ: Arquivo Público do Estado do Rio de Janeiro, 1998.

NUNES, Francivaldo Alves. Agricultura e civilização no Pará Imperial: terra, matas e povoamento. Histórica: Revista Eletrônica do Arquivo Público do Estado de São Paulo, São Paulo, n. 36, 2009

NUNES, Francivaldo Alves. O "Valor" das terras amazônicas no século XIX: questões sobre agricultura e extrativismo. SAECULUM - Revista de história, João Pessoa, n. 26, jan.-jun. 2012.

NUNES, Francivaldo Alves. Por uma arte do cultivo: Agricultura como instrumento de controle dos índios e colonos no Pará das décadas de 1840-1880. Anais do [...]. XVII Encontro de História da Anpuh-Rio. Universidade Federal Rural do Rio de Janeiro, Nova Iguaçu, 2016.

PEDROZA, Manoela. Desafios para a história dos direitos de Propriedade no Brasil. Em Perspectiva [online], PPGH/UFC, v. 2, n. 1, p. 7-33, 2016.

RODRIGUES, Pedro Parga. A experimentação literária de Machado de Assis e o tema da propriedade da terra no XIX. Revista Cantareira, Niterói (RJ), n. 28, jan.-jul. 2018.

SANTOS, Maria José. Arranjos, Lei e Consolidação do Império: Aplicação da Lei das Terras e Apropriação das Fazendas Nacionais do Rio Branco (1830-1880). 2018. Tese (Doutorado em História) - Departamento de História, Universidade Federal do Pará, Belém.

SILVA, Marcio Antônio Both da. Lei de Terras de 1850: lições sobre os efeitos e os resultados de não se condenar "uma quinta parte da atual população agrícola". Revista Brasileira de História. São Paulo, 2015.

VARELA, Laura Beck. Das Sesmarias à propriedade moderna: um estudo de história do direito brasileiro. Renovar: Rio de Janeiro, 2005.

WEINSTEIN, Bárbara. A Borracha na Amazônia: Expansão e Decadência. São Paulo: Hucitec, 1993. 